FEDERAL RESERVE BANK OF SAN FRANCISCO

WORKING PAPER SERIES

\title{
International Transmission of Japanese Monetary Shocks Under Low and Negative Interest Rates: A Global Favar Approach
}

\author{
Mark M. Spiegel and Andrew Tai \\ Federal Reserve Bank of San Francisco \\ April 2017 \\ Working Paper 2017-08 \\ http://www.frbsf.org/economic-research/publications/working-papers/wp2017-08.pdf
}

\section{Suggested citation:}

Spiegel, Mark M., Andrew Tai. 2017. "International Transmission of Japanese Monetary Shocks Under Low and Negative Interest Rates: A Global Favar Approach” Federal Reserve Bank of San Francisco Working Paper 2017-08. http://www.frbsf.org/economicresearch/publications/working-papers/wp2017-08.pdf

The views in this paper are solely the responsibility of the authors and should not be interpreted as reflecting the views of the Federal Reserve Bank of San Francisco or the Board of Governors of the Federal Reserve System. This paper was produced under the auspices of the Center for Pacific Basin Studies within the Economic Research Department of the Federal Reserve Bank of San Francisco. 


\title{
INTERNATIONAL TRANSMISSION OF JAPANESE MONETARY SHOCKS UNDER LOW AND NEGATIVE INTEREST RATES: A GLOBAL FAVAR APPROACH
}

\author{
MARK M. SPIEGEL,
}

ANDREW TAI

\begin{abstract}
We examine the implications of Japanese monetary shocks under recent very low and sometimes negative interest rates to the Japanese economy as well as three of its major trading partners: Korea, China and the United States. We follow the literature in using movements in 2-year Japanese government bond rates as proxies for changes in monetary conditions in the neighborhood of the zero lower bound. We examine the implications of shocks to the 2-year rate in a series of factor-augmented vector autoregressive - or FAVAR - models, in which both local and global conditions are proxied by latent factors generated from domestic economic indicators and weighted indicators of major trading partners, respectively. Our results suggest that shocks to 2-year Japanese rates do have substantive impacts on Japanese economic activity and inflation in conditions of low or even negative short-term rates. However, we find only modest global spillovers from Japanese monetary policy shocks, as their impact on the economic conditions of major Japanese trading partners is muted, particularly relative to the impact of innovations in 2-year U.S. Treasury yields over the same period.
\end{abstract}

Date: February 28, 2017.

Key words and phrases. monetary policy, Japan, FAVAR model, zero lower bound, negative interest rates, United States, China.

JEL classification: C3; E5, E52, E58, F37, F42.

Preliminary and incomplete draft. 11.0 Please do not quote without the authors' permission. Helpful comments were received from Joshua Aizenman, Yin Wong Cheung, Zheng Liu, Andy Rose, Toshitaka Sekine and participants at the ADBI conference on "The Implications of Negative Interest Rates for Emerging Asia." Spiegel: Mark.Spiegel@sf.frb.org. Tai: Andrew.A.Tai@sf.frb.org. The views expressed in this paper are those of the authors and do not necessarily reflect the views of the Federal Reserve Bank of San Francisco or the Federal Reserve System. 


\section{INTRODUCTION}

This paper examines the implications of recent shocks to Japanese monetary policies on its own economy and those of three of its primary trading partners, Korea, China and the United States.

Evaluation of Japanese monetary policy shocks in the current negative interest rate environment can be challenging. The Bank of Japan (BOJ) has utilized both conventional and unconventional measures recently to provide additional stimulus to its economy and escape deflation despite its low - and more recently negative - interest rate policies. Most recently, the central bank announced a 0 percent target for its 10-year Japanese government bond (JGB) yield and also committed to overshooting its two-percent inflation target. The implications of such a combination of conventional and unconventional monetary policies is particularly challenging around the zero lower bound, where movements into negative nominal rate territory may be limited and not fully reflect the expansionary implications of such commitments on agents' expectations about future financial conditions.

In response, we follow the literature [e.g. Swanson and Williams (2014)] in evaluating monetary shocks on the basis of movements in yields on longer-term assets. In our case, we concentrate on the yields on 2-year Japanese government bonds. The time series for these bonds, as well as the 2-year US Treasury rate and the BOJ Policy rate, is shown in Figure 1. It can be seen that while the nominal movements in the Japanese 2-year rate are more muted than those of the US 2-year rate over our sample period, it does move more than the BOJ policy rate. Moreover, most recently the 2-year JGB yield has gone negative, providing increased stimulus even when the policy rate remains at zero. ${ }^{1}$ As a result, we

${ }^{1}$ Since January 2016, the BOJ policy rate has also gone negative. However, we continue to follow the 2-year yields as our proxy for Japanese financial conditions because we have little experience in movements in negative nominal yields on very short-term instruments. 
conclude that the BOJ had the opportunity to pursue expansionary monetary policy even when policy rates were constrained at or near the zero lower nominal bound. As in Swanson and Williams (2014), this easing of policy could have been achieved through unconventional policies, either through long-term asset purchases or through policies that altered agents' expectations of the future policy path. The recent policy changes pursued by the BOJ appear to have been aimed at easing monetary conditions through both channels.

Given our measure of movements in Japanese monetary conditions, we then assess the implications of Japanese monetary shocks on both that country's economy, and those of three of its most important trading partners: Korea, China and the United States.

Our study follows a long literature measuring the global implications of monetary policy shocks through a VAR approach [e.g. Christiano et al. (1996), Kim (1999), and Kim (2001)]. Kim (2001) finds evidence of spillovers from U.S. monetary policy shocks among the nonU.S. G6 countries. The channel of this transmission is primarily through influences on global interest rates, rather than through trade balances. Similarly, Canova (2005) finds evidence of spillovers from US monetary policy shocks to Latin America.

These results are not surprising in light of the uniquely influential role played by the United States in the global economy. In contrast, Mackowiak (2006) examines the implications of Japanese monetary policy shocks on a number of east Asian nations from 1987 through $2002 .{ }^{2}$ Unlike the strong evidence for spillovers from US policy in the earlier literature, Mackowiak (2006) finds only a modest impact of Japanese monetary policy shocks on the economies of its Asian neighbors. Moreover, he also finds little evidence of a "beggar-thy-neighbor" effect of expansionary Japanese monetary policy. Instead, he finds that expansionary Japanese

\footnotetext{
${ }^{2}$ Mackowiak (2006) considers smaller Asian countries than those examined here, including Hong Kong, Korea, Malaysia, Philippines, Singapore and Thailand.
} 
monetary policy actually boosts exports in neighboring economies, suggesting that the impact of changes in Japanese demand overcome those expenditure-switching effects that work in the opposite direction subsequent to Japanese monetary policy shocks. ${ }^{3}$

In this paper, we concentrate on the recent 1998-2015 period, during which prevailing policy rates were either close to zero or negative. Our analysis therefore updates Mackowiak (2006). For the long period ending in 2002 in that paper, the concentration on policy rates appears to be appropriate, as there were substantive movements in policy rates over this period. However, even here policy rates were close to the zero nominal bound after the 1992 crisis. For our more recent sample, the zero nominal lower bound looms much larger, and the end of our sample even includes some experience with negative policy rates.

We examine the implications of these shocks using the global factor-augmented vector autoregression, or FAVAR, specification of Liu et al. (2017). That paper extends the FAVAR framework of Bernanke and Boivin (2003) and Bernanke et al. (2005) to evaluate sensitivities to external exchange rate shocks. As discussed by Bernanke and Boivin (2003), a FAVAR approach is particularly suited to the analysis of concepts that are imperfectly observed latent variables. As these authors note, a FAVAR approach may even be beneficial for evaluation of economic conditions in countries with relatively high data quality such as the United States, as "economic activity" is a concept that is not directly observable. The FAVAR approach provides a coherent way to mix alternative measures of economic activity, namely through factor analysis. Bernanke et al. (2005) argue that combining the data in this manner may provide superior estimates to using a single data series for each concept. Moreover, a FAVAR model avoids the need for ad hoc specification decisions, as is encountered in a

\footnotetext{
${ }^{3}$ These results are similar to those found for U.S. exchange rate shocks in Liu et al. (2017), which find a positive impact of U.S. exchange rate depreciation on major Asian trading partners, again suggesting that expenditure-switching considerations dominate terms-of-trade implications of exchange rate shocks for major Asian nations.
} 
standard vector-autoregression (VAR). ${ }^{4}$ As discussed in Fernald et al. (2014), the use of a FAVAR framework may also better reflect the information sets relevant to policymakers or used by economic agents to make decisions.

The FAVAR approach should be particularly useful for assessing economic activity in China, one of the Japanese neighbor countries we evaluate in this study. Skepticism about the accuracy of Chinese data is well-known [e.g. Fernald et al. (2015)], both due to the extensive structural changes that have taken place recently in that country and also to systematic distortions aimed at reaching output targets. ${ }^{5}$

In addition to the conventional FAVAR approach for the representation of a local conditions index (LCI), Liu et al. (2017) also estimates a latent index of foreign activity, weighted by trade volumes for a country's prominent trading partners. This country-specific "global conditions index" (GCI) provides a novel way of conditioning for changes in foreign activity and assists in isolating specific external shocks. The GCI should also prove useful for our efforts here to gauge the global impacts of Japanese monetary policy shocks. By including the GCI, the Liu et al. (2017) FAVAR can isolate the impacts of the Japanese shocks from other global developments.

Our base specification below includes an LCI, which reflects domestic economic activity proxied by the first principal component of nine indicators of domestic activity discussed in more detail below, and a country-specific GCI estimated from 11 monthly times series for the top 9 individual trading partners of each country. These series are weighted by the trade

\footnotetext{
${ }^{4}$ There is evidence, e.g. Boivin and Ng (2006), that ad hoc pre-screening methods to reduce the number of included data series might improve the out-of-sample forecasting performances of a FAVAR. However, as discussed by Bernanke, et al, using such a pre-screening method appears to gain little in terms of observed out-of-sample performances relative to all available data series.

${ }^{5}$ Lescaroux and Mignon (2009) also construct a FAVAR model of the Chinese economy, concentrating on the implications for China of oil price shocks. However, their analysis does not include the global conditions index we adopt from Liu et al. (2017).
} 
shares of each country, constructing a trade-weighted series for each measured indicator. We then follow Liu et al. (2017) in estimating the first principal component of these 11 trade-weighted indicators along with 4 common series capturing global financial conditions to construct our GCI. These activity indices prove to be plausible, capturing well global cyclical fluctuations over the course of our sample.

We then include these activity factors in a series of six-variable VARs, using the Bayesian vector-autoregression (BVAR) approach of Sims and Zha (1998). We order the 2-year JGB innovations last, which allows the policy shocks to respond contemporaneously to the other shocks in the system. Our VAR yields the impulse responses of domestic economic activity and inflation for the four countries in our study to shocks in the 2-year JGB rate.

Our Japanese VAR confirms that a positive shock to the 2-year Japanese JGB rate is associated with reduced economic activity and inflation in Japan, as well as a deterioration in the external conditions faced by the Japanese economy. Our results for the three Japanese trading partners, however, suggest only modest and insignificant impacts on local activity and inflation. These results as a group suggest that the primary implications of Japanese monetary policy shocks are internal.

To further gauge the relative impacts of Japanese monetary policy shocks, we examine a forecast error variance decomposition for Japan and the the other countries in our study. We confirm that Japanese 2-year JGB shocks have notable influences on Japanese economic activity and inflation, but much less influence for the other countries in our study. We observe much smaller impacts of shocks to the Japanese 2-year rate than we do for shocks to the U.S. 2-year rate, even for local activity in the Japanese economy itself. We do get some surprising results for the relative impacts of policy shocks on inflation in some of the countries. However, we consider these implausible as we discuss below. 
Overall, our results suggest that Japanese interest rates do not influence global economic conditions as acutely as movements in U.S. rates do. This is unsurprising, as the dollar has been identified as the primary reserve currency which drives the "global financial cycle," [e.g. Agrippino and Rey (2015)]. Prima facie, unlike their U.S. counterparts, this lack of global influence may free Japanese policy makers to tailor their decisions to domestic concerns without consideration of potential global spillovers. Our results for Japan's low and negative interest rate period using movements in 2-year yields as proxies for Japanese monetary policy shocks largely confirm those found in Mackowiak (2006) for an earlier time period based on directly observable movements in policy rates.

The remainder of this paper is organized into 5 sections. Section 2 discusses our empirical methodology and our construction of the local and global activity indices for the four countries in our study. Section 3 estimates the FAVAR model and discusses our results. Section 4 conducts some robustness tests. Lastly, section 5 concludes.

\section{EMPIRICS}

II.1. Methodology. We estimate the implications of a Japanese monetary policy shock for economic activity using a FAVAR approach, in the spirit of Bernanke and Boivin (2003) and Bernanke et al. (2005). Observed individual time series, such as industrial production and the unemployment rate, are imperfect measures of economic activity. This is particularly true for countries like China, where data availability is limited and official data have not been considered completely reliable [e.g. Fernald et al. (2014)]. The FAVAR framework can accommodate these data challenges by pooling the information available from a variety of potentially noisy sources. Moreover, this approach leaves only a modest number of parameters to be estimated in our VAR representation. 
We follow Liu et al. (2017) in measuring domestic activity as a latent variable, which is extracted from a wide range of published time-series data. We term this latent variable our "local conditions index" (LCI). To construct the LCI for each country, we extract the first principal component of a number of domestic economic indicators in that country. The observables are related to the factors through the following specification

$$
X_{t}=\Lambda F_{t}+u_{t}
$$

where $X_{t}$ represents the observable indicators and $F_{t}$ represents underlying factors, while $u_{t}$ denotes idiosyncratic noises and $\Lambda$ is the matrix of factor loading parameters. For each country, the observable data $X_{t}$ is a vector of nine domestic variables, including industrial production, unemployment, housing starts or permits, stock prices, 1-year government bond yields, 2-year government bond yields, M1, M2, and the producer price index. ${ }^{6}$

We also follow Liu et al. (2017) in estimating a latent variable representing external conditions, which we term a "global conditions index" (GCI). The GCI is generated from indicators collected from each country's major trading partners, weighted by trade volume. This series includes similar variables to those in the LCI for each trading partner country, as well four "common" variables representing overall global conditions. Indicator variables included are industrial production, unemployment, the consumer price index, housing starts or permits, equity prices, 1-year government bond yields, 2-year government bond yields, 3-month government bond yields, M1, M2, and the producer price index. ${ }^{7}$ We then compute the principal components of trade-weighted averages of those 11 time series plus four common series (oil

\footnotetext{
${ }^{6}$ See the Appendix for a description of the data. Some of the variables included in the construction of the GCI, such as the consumer price index, are not included in the LCI because they are introduced as separate arguments in our final VAR specification.

${ }^{7}$ The Appendix describes the time series data used and provides a list of the each country's largest trading partners.
} 
prices, the emerging market bond yield index, the economic sentiment indicator of the euro zone, and the economic sentiment indicator of the European Union). The GCI is measured as the first principal component. ${ }^{8}$

Our base FAVAR specification includes the 2-year U.S. Treasury bill rate, the Japan LCI, the inflation rate (measured by year-over-year changes in the consumer price index), the Japan GCI, the broad trade-weighted Japanese yen, and the Japanese 2-year government bond rate, in that order. This ordering of the variables reflects our Cholesky identification restriction that the other factors do not respond to a shock to the 2-year rate in the impact period, while the 2-year rate is allowed to respond to the other shocks. We estimate the impulse responses using Bayesian methods with Sims and Zha (1998) priors. ${ }^{9}$

Figure 2 displays the LCI and GCI for Japan. The grey areas represent the U.S. Great Recession. The Japanese LCI and GCI both appear to be plausible, and in particular reflect the impact of the global financial crisis and the downturn in Japan during the crisis and the recovery afterwards. Japan's LCI and GCI are closely correlated, with a steep drop in the Japanese GCI during the great recession, while the falloff in the Japanese activity indicator during that period is surprisingly tranquil relative to the steep drops in trade and GDP experienced by Japan during that episode [e.g. Rose and Spiegel (2012)].

Both Japan's LCI and GCI appear to pick up around the middle of 2013, presumably in response to optimism surrounding the election of Shinzo Abe as Prime Minister and the launching of his "Abenomics" economic reforms. In particular, we see a substantive pickup after the formal adoption of inflation targeting by the BOJ in 2013, which is marked in

\footnotetext{
${ }^{8}$ The first principal component of the LCI accounts for $31 \%$ of the variance of the LCI for Japan, $49 \%$ for the US, $33 \%$ for Korea, and 39\% for China. The first principal component of the GCI accounts for about $41 \%$ of the variance of the GCI for each country. The explanatory powers of the 2 nd principal components are substantially smaller, approximately $21 \%$ for the US, $20 \%$ for Japan, $19 \%$ for Korea and $20 \%$ for China. ${ }^{9}$ An advantage of using the Sims and Zha (1998) priors is that accuracy is improved when the time series dimension of the sample is relatively short, as in our paper.
} 
Figure 2. However, Japan's LCI and GCI pickups are almost completely reversed by the end of our sample.

\section{Results}

III.1. The Japan FAVAR model. Our FAVAR specification for Japan includes the 2-year U.S. Treasury bill rate, the Japan local conditions index, the inflation rate (measured by year-over-year changes in the consumer price index), the Japan global conditions index, the broad trade-weighted Japanese yen, and the Japanese 2-year government bond rate, in that order.

Figure 3 shows the estimated impulse responses in the Japanese FAVAR model to an one standard deviation shock in the Japanese 2-year government bond rate. The solid lines represent the median impulse responses and the dashed lines show the range of the $68 \%$ confidence bands.

The rise in Japanese rates is followed by a decline over time to both Japanese domestic activity as measured by the LCI and inflation, as would be expected. We also see a significant decline in Japan's GCI and a persistent increase in the value of the yen. The activity and inflation variables return to their initial values within four years, but the yen is more persistent. Still, even that variable appears to be returning to its steady state level.

In short, our VAR results suggest that a Japanese monetary shock that succeeds in moving the 2-year rate would move the aggregate Japanese variables in the expected manner and have significant effects, even over this period of low and negative prevailing short-term rates.

To estimate the importance of Japanese monetary policy shocks over our estimation period, we next estimate the forecast error variance of each of the variables included in our VAR in response to a shock in the Japanese 2-year rate. 
Our results are shown in Table 1. Movements in the 2-year rate contribute substantially to all of the Japanese macroeconomic variables at 1 and 2 year horizons. As would be expected, the 2-year rate drives most of the variation in the value of the Japanese yen, with shocks to the 2-year rate explaining over 70 percent of fluctuations in yen values. However, it also influences real activity, as 2-year rate shocks explain over 6 percent of variation in the LCI, inflation, and Japan's GCI with a 1 year lag, and reach values as high as 13.8\%, 15.6\%, and $9.6 \%$ respectively at a 36 month horizon.

\section{III.2. FAVAR models for Japanese trading partners.}

III.2.1. Korea FAVAR model. We next turn to the case of Korea. Figure 4 shows the impulse responses and the $68 \%$ confidence bands in the estimated Korean FAVAR model. Our specification is the same as that used for Japan, including the US 2-year rate, Korea's LCI, CPI inflation rate, GCI, the won real exchange rate, and the Japanese 2-year rate, in that order. $^{10}$

As shown in Figure 4, movements in Korean variables in response to shocks to the Japanese 2-year rate are very muted. We see only modest movements in economic activity and inflation, neither of which are statistically significant at even a $68 \%$ confidence level. There is also a modest response in Korea's GCI, which appears to be only modestly significantly positive at its peak around 6 months after the shock took place. Still, the point estimates for the GCI impulse response function at that point is below 0.1 standard deviations.

The one variable that clearly does respond to the Japanese 2-year shock is the Korean real exchange rate, which depreciates as expected given the strong response we found for the

\footnotetext{
${ }^{10}$ In our Korea VAR, and in the China and US VARs as well, we use the real exchange rate rather than the nominal one. The real exchange rate is more relevant for the impact of shocks to Japanese monetary policy on economic activity in other countries, because it directly influences terms of trade.
} 
Japanese yen to the 2-year rate shock. This movement in the Korean real exchange rate is probably behind the modest increase that we observe in the Korean GCI.

Finally, we do see a modest, but marginally statistically significant temporary increase in the US 2-year rate. It seems implausible to us that shocks to the Japanese 2-year government bonds could have such an impact on U.S. treasury rates. Instead, there may be other relationships, such as the intensity of carry trade activity, that are driving both results. This case would correspond to the situation where some variable outside our VAR specification was simultaneously moving both of these yields. Thus, we do not draw any strong inferences from the US 2-year impulse response function. It was introduced primarily to draw a contrast between our observed responses to the Japanese 2-year government bond rate to those from shocks to the US 2-year Treasury rate below.

III.2.2. China FAVAR model. We next turn to the case of China. Our VAR specification remains the same, including the US 2-year rate, Chinas's LCI, CPI inflation rate, GCI, the renminbi real exchange rate, and the Japanese 2-year rate, in that order. Figure 5 shows the impulse responses and the $68 \%$ confidence bands in our estimated FAVAR specification.

Our qualitative results for China are similar to those that we obtained for Korea. In particular, there is a modest decline in Chinese inflation and a modest increase in inflation, but these are usually insignificant. We observe an even more modest response in the Chinese GCI than we observed for Korea, probably explainable by the much more modest impulse response that we observe for the Chinese real exchange rate. Because the Chinese renminbi was at least stabilized against the dollar over our sample period, and tightly linked for most of it, the broad Chinese real exchange rate is shown to be largely unresponsive to movements 
in the Japanese yen, and by association, to shocks to the Japanese 2-year government bond rate.

Comparing China's impulse response functions to those of Korea, one can see that although their general patterns are similar, the impacts on both Chinese LCI's and inflation appear to be less persistent. This distinction is intuitive, as China's managed exchange rate regime and its largely closed capital account leave it relatively more insulated from shocks to Japanese monetary policy.

III.2.3. US FAVAR model. Finally, we turn to our US VAR specification. The specification remains the same, including the US 2-year rate, Korea's LCI, CPI inflation rate, GCI, the US dollar real exchange rate, and the Japanese 2-year rate, in that order. Figure 7 shows the impulse responses and the $68 \%$ confidence bands in our estimated FAVAR specification.

Our estimated responses for the US LCI are even more modest than those we found for Korea and China. We observe almost no movement in response to a shock to the Japanese 2-year rate. We do observe a modest decline in the US inflation rate, which would follow from the exchange rate appreciation in Japan feeding into the price of US imports from that country. However, the US real exchange rate, if anything, surprisingly appears to appreciate over this period. As such, there may be some other feature outside our specification that is driving both of these variables, and we don't place strong confidence in our inflation results.

III.2.4. Comparison with US 2-year shocks. Overall, our FAVAR specifications appear to indicate that while Japanese monetary shocks over this period do influence domestic Japanese conditions, their impact on Japan's major trading partners is modest. This can be confirmed by comparing the forecast error variance decompositions for the impact of shocks to the 2year Japanese government rate to those for shocks to the 2-year U.S. Treasury bill rate, which 
is commonly considered an indicator of global financial conditions in the neighborhood of the zero lower bound. That is done in Table 2, which examines the implications of these two shocks for the LCI's and inflation rates of the four nations in our study.

We first look at shocks to the LCI's from Japanese and U.S. 2-year rates. As the impact is constrained to be zero for Japanese shocks in the first period, we concentrate on relative impacts over 12 and 24 month periods. Here, one can clearly see the relative dominance of shocks to the U.S. 2 year rate.

The dominance of the U.S. shocks in explaining the U.S. LCI is no surprise. Shocks to the Japanese 2-year rate only explain 0.68 and 0.61 percent of the variability in the U.S. LCI at 12 and 24 month horizons respectively, while shocks to the U.S. 2-year rate explain 14.15 and 23.37 percent of U.S. variability at those same horizons respectively.

However, the U.S. 2-year also dominates for other countries in our study. At a 12 month horizon, shocks to the Japanese 2-year rate explain only 1.5 and 2.2 percent of the variability in Korean and Chinese LCIs, while shocks to the U.S. 2-year rate explain 4.2 and 6.2 percent of the variability in the LCIs of those countries respectively. At a 24 month horizon, the discrepancy is even larger. Shocks to the Japanese 2-year rate explain only 1.6 and 3.9 percent of the variability in Korean and Chinese LCIs, while shocks to the U.S. 2-year rate explain 8.7 and 4.4 percent of the variability in the LCIs of those countries respectively.

But the most surprising results are those that we obtain for the Japanese economy itself. At 12 and 24 month horizons, shocks to the Japanese 2-year rate explain 0.34 and 8.04 percent of the variability in the Japanese LCI respectively, while shocks to the U.S. 2-year rate explain 22.78 and 33.11 percent of the variability in the Japanese LCI respectively. Shocks to the Japanese 2-year JGB rate appear to affect even the Japanese economy much less shocks to the 2-year U.S. Treasury rate. 
With the exception of the United States, we obtain similar results for inflation. The U.S. results are quite surprising, and frankly implausible, as our estimates indicate that shocks to the U.S. 2-year rate only explain 1.66 and 4.51 percent of the variability in US inflation over 12 and 24 month horizons, while shocks to 2-year JGBs explain 6.22 percent and 4.78 percent of the variability respectively over 12 and 24 month horizons. Given the significant correlation identified earlier between the 2-year JGB rate and the broad Japanese yen, it is possible that there is some channel for 2-year Japanese government bond rates to feed into US inflation, but it seems implausible that it would have a larger impact than a shock to the 2-year US Treasury rate. As such, we consider this result the primary puzzle that emerged from our study, as most of our other FAVAR results have come in largely as would be expected.

That is certainly true for the impact of 2-year rate shocks to Korean and Chinese inflation rates. Given that shocks to the Japanese 2-year rate had notably smaller impacts on Korean and Chinese output as measured by those countries' LCIs than shocks to 2-year US Treasuries, we would also expect that to be the case for inflation in those countries. As shown in Table 2, that proves to be true. At a 12 month horizon, shocks to the Japanese 2-year rate explain only 0.48 and 3.23 percent of the variability in Korean and Chinese inflation, while shocks to the U.S. 2-year rate explain 7.10 and 2.83 percent of the variability in inflation of those countries respectively. At a 24 month horizon, shocks to the Japanese 2-year rate explain only 4.83 and 5.26 percent of the variability in Korean and Chinese inflation, while shocks to the U.S. 2-year rate explain 8.63 and 8.87 percent of the variability in the LCIs of those countries respectively.

We also again obtain the surprising result that movements in the US 2-year Treasury rate actually appear to move Japanese macro variables, in this case inflation, more than their 
Japanese counterparts. At a 12 month horizon, shocks to the Japanese 2-year rate explain only 0.93 percent of Japanese inflation, while shocks to the US 2-year Treasury rate explain 6.79 percent. At a 24 month horizon the impacts are closer, with Japanese 2-year rate shocks explaining 6.08 percent of variability in Japanese inflation, but the US 2-year effect is still stronger, explaining 6.40 percent of Japanese inflation variability.

There are a few surprises in our inflation results, particularly the strong impact of Japanese shocks on U.S. inflation. However, our inflation results overall confirm those we obtain for output, namely that shocks to the Japanese 2-year rate do not move global macroeconomic variables nearly as much as shocks to 2 -year Treasury rates. ${ }^{11}$

\section{Robustness CHECKS}

In this section, we consider some perturbations of our base specification to examine the robustness of our results. First, we drop the interest rate variables from our LCI specification for Japan to ensure that no spurious correlation between shocks to the 2-year JGB rate and the Japanese LCI arise because of the inclusion of Japanese interest rates in our LCI estimation. Second, we reorder our specification to put the exchange rate last.

IV.1. Alternative Japanese LCI specification. Our base LCI specification is constructed by taking the first principal component of a number of indicator variables, which includes one and two-year JGB yields. As these are introduced through a principal component, there is no prima facie reason to expect that their inclusion yields spurious correlations between

\footnotetext{
${ }^{11}$ Recently, the BOJ has engaged in yield curve management, targeting the 10-year JGB yield as part of its unconventional monetary policy. As a robustness check, we substituted shocks to the 10-year yield for the 2 -year yield shocks in our base specification. Our qualitative results were the same. Shocks to the 10-year rate move Japanese economic activity and inflation in the same manner as the results we found here for 2-year rate shocks, but do not impact on the other countries in our study. These results were provided to the referees and are available from the authors upon request.
} 
our Japanese LCI estimates and 2-year JGB shocks. Still, to make sure that this is not the case, we reestimate our Japanese LCI with these yields excluded.

Our impulse response functions with this alternative LCI index are shown in Figure 7. Our qualitative results are largely unchanged. In particular, we continue to find that a positive shock to the Japanese 2-year rate is followed by a decline over time in both Japanese domestic activity as measured by the LCI and Japanese inflation. We also continue to see a decline in Japan's GCI and a persistent increase in the value of the yen. The activity and inflation variables continue to return to their initial values within four years, and the impact on the yen remains more persistent. However, while our qualitative point estimates for the impulse response functions are largely the same, our alternative specification displays much wider confidence bands, resulting in statistical insignificance at a $68 \%$ confidence level for most variables.

To gauge the relative importance of the Japanese 2-year rate on Japanese variables in this alternative specification, We also reestimate the forecast error variance of each of the variables included in our VAR in response to shocks in the 2-year US Treasury rate and in the Japanese 2-year rate.

Our results are shown in Table 3. Our qualitative results for the relative importance of Japanese 2-year rate shocks remain unchanged, as the U.S. 2-year shocks continue to dominate the Japanese 2-year shocks in explaining both Japanese domestic activity and inflation. $^{12}$

\footnotetext{
${ }^{12}$ We also examined the specification with JGB yields excluded from both the LCI and the GCIs. Overall, our qualitative results were largely unchanged. However, it appears to be the case that our estimated confidence intervals were larger, with the result that under this alternative specification we fail to find significant impacts of shocks to the Japanese 2-year rate on the Japanese LCI and inflation as well. These results are available upon request from the authors.
} 
IV.2. Alternative VAR specification. As a further robustness check of our results, we follow Mackowiak (2006) in considering an alternative VAR ordering, namely ordering the exchange rate last and the 2-year JGB rate next-to-last. Mackowiak (2006) associate this alternative specification with Christiano et al. (1999), who argue that monetary authorities do not possess complete information, and therefore respond to some variables only with a lag. Our alternative specification implies that the Japanese 2-year rate can only respond to shocks to the Japanese exchange rate after a one-period lag. ${ }^{13}$

We summarize our impulse response results for this alternative specification in Figure 8, which list the LCI and inflation impulse response functions for all four countries in our study in response to a shock in the Japanese 2-year rate. Our results are quite similar to those in our base specification. We continue to find a lagged negative and statistically significant response in both the Japanese LCI and inflation. In contrast, the responses of the other countries in our study to the 2-year Japanese government bond shock are modest and largely insignificant.

To gauge the relative importance of the Japanese 2-year rate on Japanese variables in this alternative specification, We also re-estimate the forecast error variance of each of the variables included in our VAR in response to shocks in both the 2-year US Treasury rate and in the Japanese 2-year rate.

Our results are shown in Table 4. The qualitative results remain unchanged: The U.S. 2-year shocks continue to dominate the Japanese 2-year shocks in explaining the variability of Japanese domestic activity as proxied by the Japanese LCI at a 12 month horizon. For inflation, the results are again more mixed. For the other countries in our sample, the 2-year

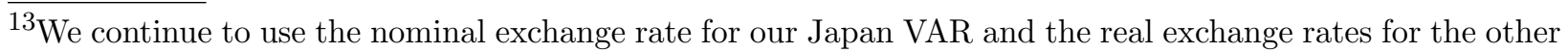
VARs in our study.
} 
US Treasury shock is usually dominant in explaining economic activity, but the inflation results for the US are again more mixed.

\section{Conclusion}

We evaluate the implications of a Japanese monetary policy shock at low or negative shortterm rates as proxied by a shock to the Japanese 2-year rate. We examine the dynamics of the responses to a 2-year JGB rate shock using a FAVAR framework in which both local and global conditions are proxied by latent factors generated from the economic indicators of domestic and major trading partners respectively. Our results indicate that shocks to the Japanese 2-year government bond rate affect the Japanese economy in the predicted manner, with statistically-significant downward pressure on economic activity and inflation, but that shocks to the Japanese 2-year rate have only a modest impact on economic activity in the other countries in our study. Our results therefore cast doubt on the contention that efforts by Japan to stimulate its economy through easy monetary policy will have "beggar thy neighbor" implications for Japan's primary trading partners. Interestingly, these results largely confirm the earlier study by Mackowiak (2006), which was conducted over much more normal periods with more standard methodologies.

Some caveats are in order. First, our analysis considers the implications of a shock to the 2-year JGB, which is not a directly-controlled policy instrument of the BOJ. As such, they do not directly speak to the merits of the set of policies available to the BOJ at low or negative short-term rates. We can only draw conclusions from our results about actual policies, including long-term asset purchases or forward guidance concerning policy rates if such policies were known to move Japanese 2-year rates in a predictable manner. Such knowledge is challenging to acquire, however, as the Japanese government typically pursued 
a number of policies simultaneously. Moreover, the implications of unconventional policies pursued by the Bank of Japan (and others) remain unclear at this time.

Second, our forecast error variance decompositions, which indicate a relatively modest role for shocks to the 2-year JGB rate, are based on the conditions prevailing over our relatively recent sample period. In particular, over this period of very low or even negative nominal short-term rates in Japan, observed shocks to the 2-year rate were generally modest in size. This modest shock size contributed to the inference drawn above that movements in the 2-year JGB rate contributed relatively little to observed variability in economic activity and inflation for the countries we study over our sample period. However, they do not imply that a policy yielding larger shocks to the 2-year rate would not have substantial effects. 
TABle 1. Forecast Error Variance: Japanese Activity from Japan 2-yr

\begin{tabular}{cccccc}
\hline \hline Months & LCI & Inflation & GCI & Broad Japan yen & Japan 2 yr \\
\hline 1 & 0.00 & 0.00 & 0.00 & 0.00 & 42.16 \\
12 & 0.34 & 0.93 & 2.02 & 86.54 & 17.71 \\
24 & 8.04 & 6.08 & 7.74 & 77.89 & 12.35 \\
36 & 13.84 & 15.57 & 9.57 & 70.67 & 13.18 \\
\hline
\end{tabular}

Note: Share of error variances at indicated horizons for shocks to 2-year JGBs and US Treasury Bills respectively. 
TABLE 2. Forecast Error Variance: Effects of US and Japan 2-yr

\begin{tabular}{c|cccc|cccc}
\hline \hline \multicolumn{10}{c}{ Global LCIs } \\
\hline \multicolumn{10}{c}{ Impact of JPN 2y } & \multicolumn{4}{c}{ Impact of US 2y } \\
\hline Months & Japan & Korea & China & United States & Japan & Korea & China & United States \\
1 & 0.00 & 0.00 & 0.00 & 0.00 & 5.53 & 4.37 & 0.25 & 9.98 \\
12 & 0.34 & 1.52 & 2.24 & 0.68 & 22.78 & 4.16 & 6.18 & 14.15 \\
24 & 8.04 & 1.58 & 3.94 & 0.61 & 33.11 & 8.65 & 4.42 & 23.37 \\
36 & 13.84 & 1.64 & 5.53 & 3.23 & 33.83 & 7.22 & 4.42 & 21.12 \\
\hline \hline \multicolumn{8}{c}{ Impact of JPN 2y } & Inflation \\
\hline \multicolumn{10}{c}{ Korea } & China & United States & Japan & Korea & China & United States \\
1 & 0.00 & 0.00 & 0.00 & 0.05 & 0.02 & 1.95 & 0.13 \\
12 & 0.93 & 0.48 & 3.23 & 6.22 & 6.79 & 7.10 & 2.83 & 1.66 \\
24 & 6.08 & 4.83 & 5.26 & 4.78 & 6.40 & 8.63 & 8.87 & 4.51 \\
36 & 15.57 & 7.43 & 4.79 & 4.88 & 6.00 & 11.83 & 8.07 & 6.65 \\
\hline
\end{tabular}

Note: Share of error variances at indicated horizons for shocks to 2-year JGBs and US Treasury Bills respectively. 
TABLE 3. Forecast Error Variance: Effects US and Japan 2-year with alternative LCI

\begin{tabular}{c|cc|cc}
\hline \hline & \multicolumn{2}{|c|}{ Impact of US 2y } & \multicolumn{2}{c}{ Impact of JPN 2y } \\
\hline Months & Local conditions & Inflation & Local conditions & Inflation \\
1 & 4.45 & 0.15 & 0.00 & 0.00 \\
12 & 18.94 & 5.90 & 0.55 & 0.46 \\
24 & 19.85 & 5.83 & 0.49 & 1.64 \\
36 & 18.56 & 5.12 & 0.52 & 2.65 \\
\hline
\end{tabular}

Note: Share of error variances at indicated horizons for shocks to 2-year JGBs and US Treasury Bills respectively. 
TABLE 4. Forecast Error Variance: Effects of US and Japan 2-yr with exchange rates last

\begin{tabular}{|c|c|c|c|c|c|c|c|c|}
\hline \multicolumn{9}{|c|}{ Global LCIs } \\
\hline & \multicolumn{4}{|c|}{ Impact of JPN $2 y$} & \multicolumn{4}{|c|}{ Impact of US $2 y$} \\
\hline Months & Japan & Korea & China & United States & Japan & Korea & China & United States \\
\hline 1 & 0.00 & 0.00 & 0.00 & 0.00 & 5.53 & 4.37 & 0.25 & 9.98 \\
\hline 12 & 0.36 & 3.05 & 2.28 & 0.30 & 22.78 & 4.16 & 6.18 & 14.15 \\
\hline 24 & 7.58 & 3.07 & 4.04 & 0.58 & 33.11 & 8.65 & 4.42 & 23.37 \\
\hline 36 & 12.95 & 2.87 & 5.80 & 4.07 & 33.83 & 7.22 & 4.42 & 21.12 \\
\hline \multicolumn{9}{|c|}{ Inflation } \\
\hline & \multicolumn{4}{|c|}{ Impact of JPN 2y } & \multicolumn{4}{|c|}{ Impact of US $2 y$} \\
\hline Months & Japan & Korea & China & United States & Japan & Korea & China & United States \\
\hline 1 & 0.00 & 0.00 & 0.00 & 0.00 & 0.05 & 0.02 & 1.95 & 0.13 \\
\hline 12 & 0.75 & 2.82 & 3.16 & 4.12 & 6.79 & 7.10 & 2.83 & 1.66 \\
\hline 24 & 6.16 & 2.65 & 5.33 & 3.18 & 6.40 & 8.63 & 8.87 & 4.51 \\
\hline 36 & 15.61 & 3.92 & 4.86 & 3.42 & 6.00 & 11.83 & 8.07 & 6.65 \\
\hline
\end{tabular}

Note: Share of error variances at indicated horizons for shocks to 2-year JGBs and US Treasury Bills respectively. Since the US 2-year Treasury is the first variable in the VAR specifications, the decomposition of its impact is the same as in Table 2 


\section{Appendix A. DAta DESCRIPtions}

A.1. Local conditions index. We construct local conditions indices (LCI) for the United States, South Korea, Japan and China based on a number of monthly time series data. In particular, each country's LCI is the first principal component of the following series:

(1) Industrial production (log growth)

(2) Unemployment rate

(3) Housing starts/permits (log unit)

(4) Stock price index (log growth)

(5) One-year government bond yields

(6) Two-year government bond yields

(7) M1 (log growth)

(8) M2 (log growth)

(9) Producer price index (log growth).

For China, the samples for the two-year and one-year government bond yields are very short. We replace them by China's interbank loan rates.

A.2. Global conditions index. We construct global conditions indices (GCI) for each country based on trade-weighted averages of 11 time series variables in that country's major trading partners along with four common series.

The 11 country-specific variables include

(1) Industrial production (log growth)

(2) Unemployment rate

(3) Consumer price index (log growth)

(4) Housing starts/permits (log)

(5) Stock price index (log growth)

(6) One-year government bond yields

(7) Two-year government bond yields

(8) Three-month government bond yields

(9) M1 (log growth) 
(10) M2 (log growth)

(11) Producer price index (log growth)

The four common series include

(1) Brent crude oil price (log)

(2) Emerging market bond yield index, EMBI

(3) European Commission Economic SentiMent Indicator Eurozone

(4) European Commission Economic SentiMent Indicator EU

To construct the GCI for a country, we compute the first principal component of the 11 trade-weighted series plus the four common series. We focus on the 9 largest trading partners determined by total trade (imports plus exports) in 2014, so that the composition of the trading partners remain constant over time. All trade data are taken from the IMF Direction of Trade Statistics database. Table ?? shows the top 9 major trading partners of each country in our sample. + 


\section{REFERENCES}

Agrippino, S. M. And H. Rey (2015): "World Asset Markets and the Global Financial Cycle," NBER Working Paper 21722.

Bernanke, B. S. And J. Boivin (2003): "Monetary Policy in a Data-Rich Environment," Journal of Monetary Economics, 50, 525-546.

Bernanke, B. S., J. Boivin, And P. Eliasz (2005): "Measuring the Effects of Monetary Policy: A Factor-Augmented Vector Autoregressive (FAVAR) Approach," Quarterly Journal of Economics, 120, 387-422.

Boivin, J. And S. NG (2006): “Are More Data Always Better for Factor Analysis?" Journal of Econometrics, 132, 169-194.

Canova, F. (2005): "The Transmission of U.S. Shocks to Latin Data," Journal of Applied Econometrics, 20, 229-251.

Christiano, L. J., M. Eichenbaum, and C. L. Evans (1996): "The Effects of Monetary Policy Shocks: Evidence from the Flow of Funds," The Review of Economics and Statistics, $78,16-34$.

(1999): "Monetary Policy Shocks: What Have We Learned and to What End?" in Handbook of Macroecnomics, ed. by J. Taylor and M. Woodford, New York, NY: Elsevier.

Fernald, J. G., E. Hsu, And M. M. Spiegel (2015): "Is China Fudging Its Figures?: Evidence from Trading Partner Data," Federal Reserve Bank of San Francisco.

Fernald, J. G., M. M. Spiegel, And E. T. Swanson (2014): "Monetary Policy Effectiveness in China: Evidence from a FAVAR Model," Journal of International Money and Finance, 49 (A), 83-103.

Kim, S. (1999): "Do Monetary Policy Shocks Matter in the G-7 Countries? Using Common Identifying Assumption about Monetary Policy Across Countries," Journal of International Economics, 48, 387-412.

_ (2001): "International Transmission of U.S. Monetary Policy," Journal of Monetary Economics, 48, 339-372. 
Lescaroux, F. And V. Mignon (2009): "Measuring the Effects of Oil Prices on China's Economy: A Factor-Augmented Atuoregressive Approach," Pacific Economic Review, 14, 410-425.

LiU, Z., M. M. Spiegel, AND A. TAi (2017): "Measuring the Effects of Dollar Appreciation on Asia: A FAVAR Approach," Forthcoming, Journal of International Money and Finance.

Mackowiak, B. (2006): "What Does the Bank of Japan do to East Asia?" Journal of International Economics, 70, 253-270.

Rose, A. K. And M. M. Spiegel (2012): "Cross-Country Causes and Consequences of the 2008 Crisis: Early Warning," Japan and the World Economy, 24, 1-16.

Sims, C. A. And T. Zha (1998): "Bayesian Methods for Dynamic Multivariate Models," 39, 949-968.

Swanson, E. T. And J. C. Williams (2014): "Measuring the Effect of the Zero Lower Bound on Medium- and Longer-Term Interest Rates," American Economic Review, 104, 3154-3185. 


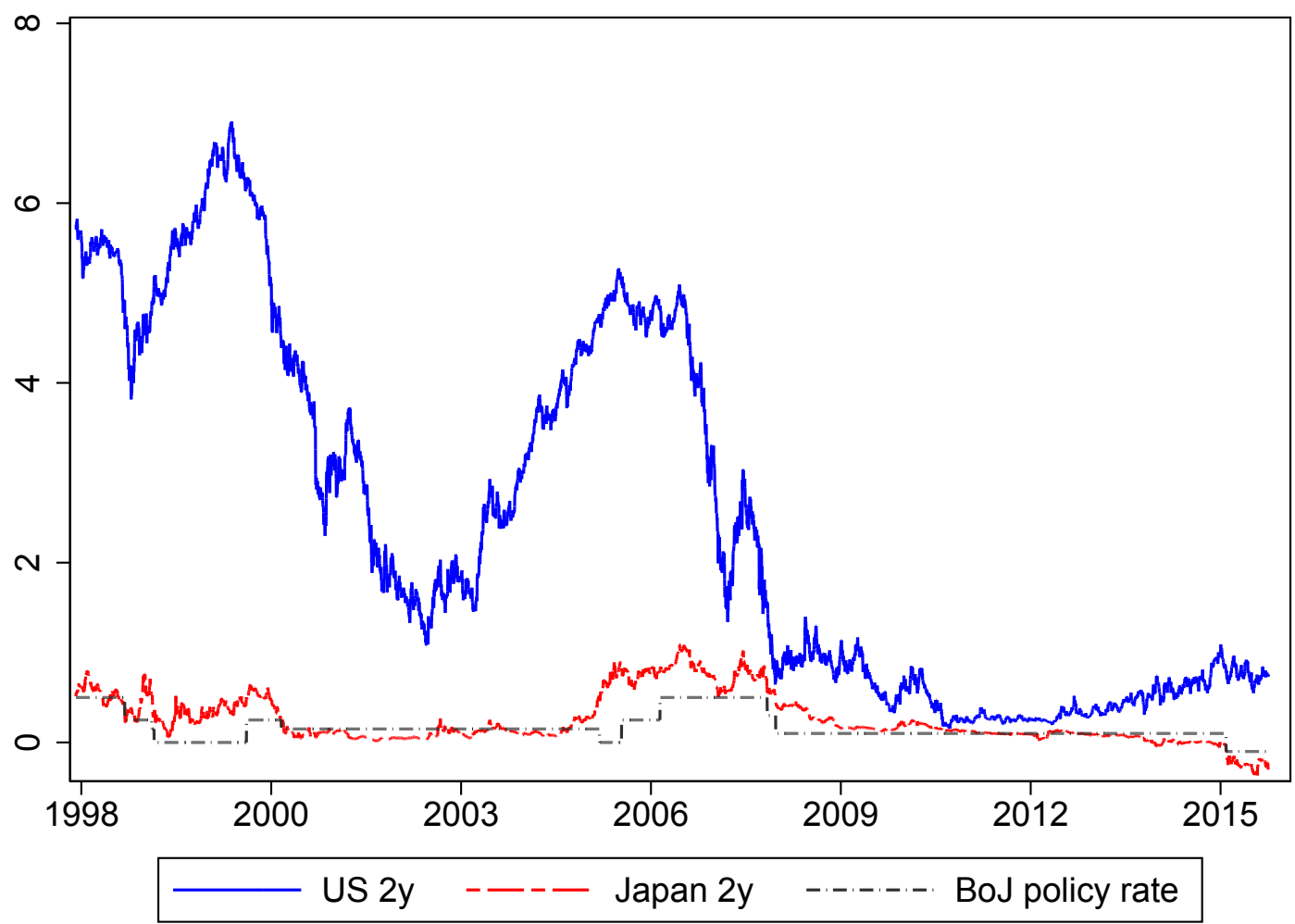

Figure 1. Japan Government Bond Yields and Bank of Japan Policy Rate 1998-2016.

Federal Reserve Bank of San Francisco 


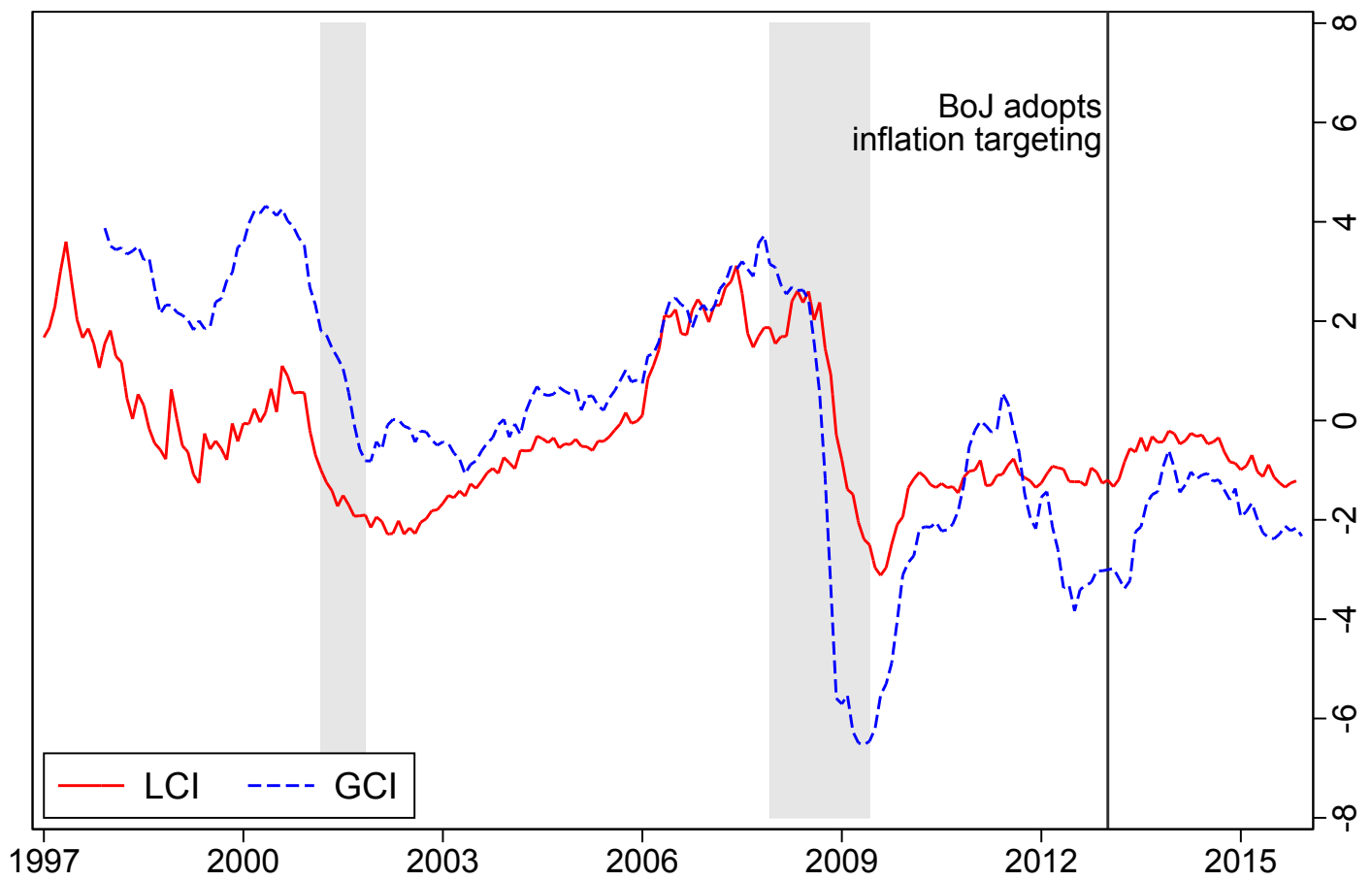

Figure 2. Japan Local and Global Conditions Indices 1998-2016. 

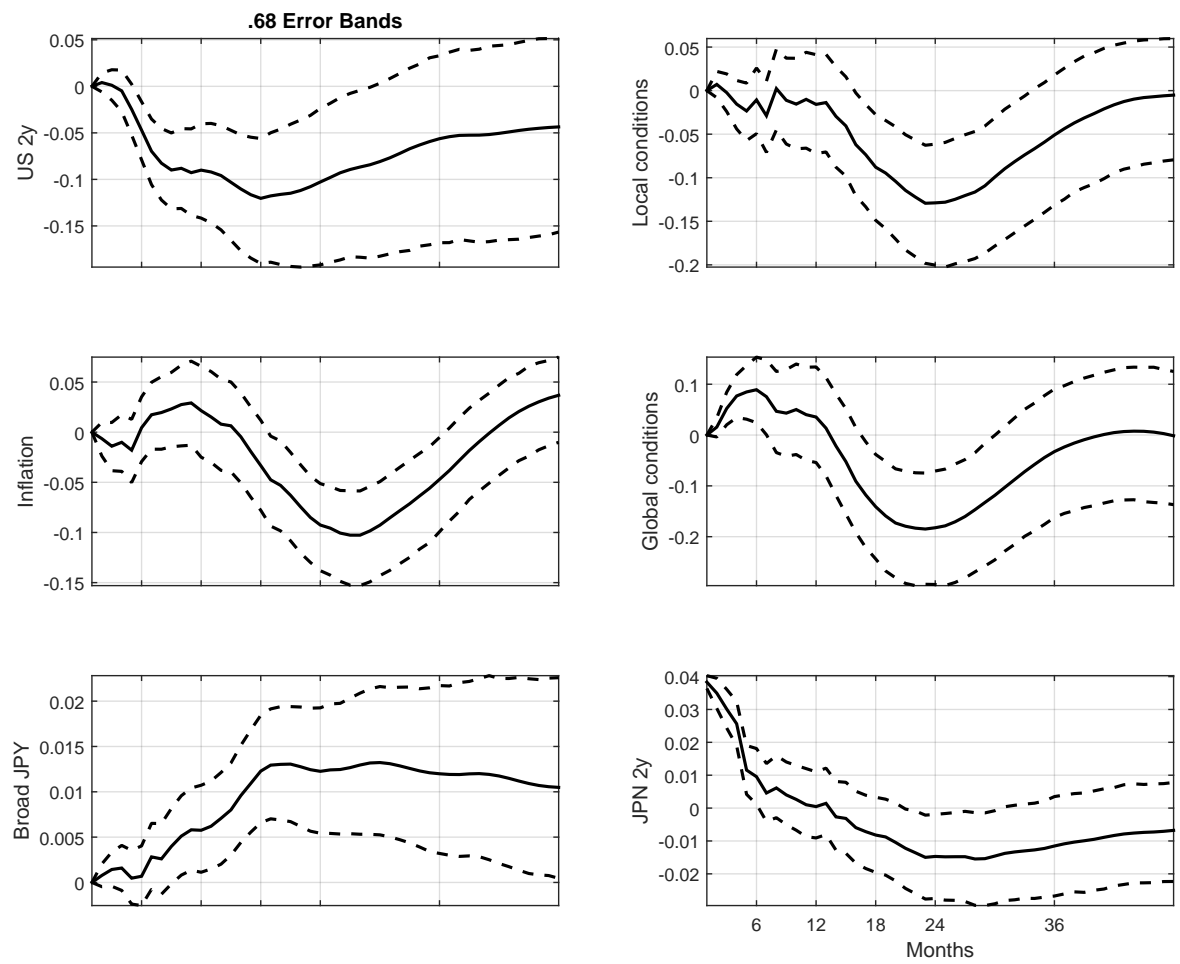

Figure 3. Japan Impulse Response Functions. Impulse responses to a positive shock to the Japan 2-year rate. The solid lines represent estimated impulse responses; dashed lines are $68 \%$ confidence bands. 

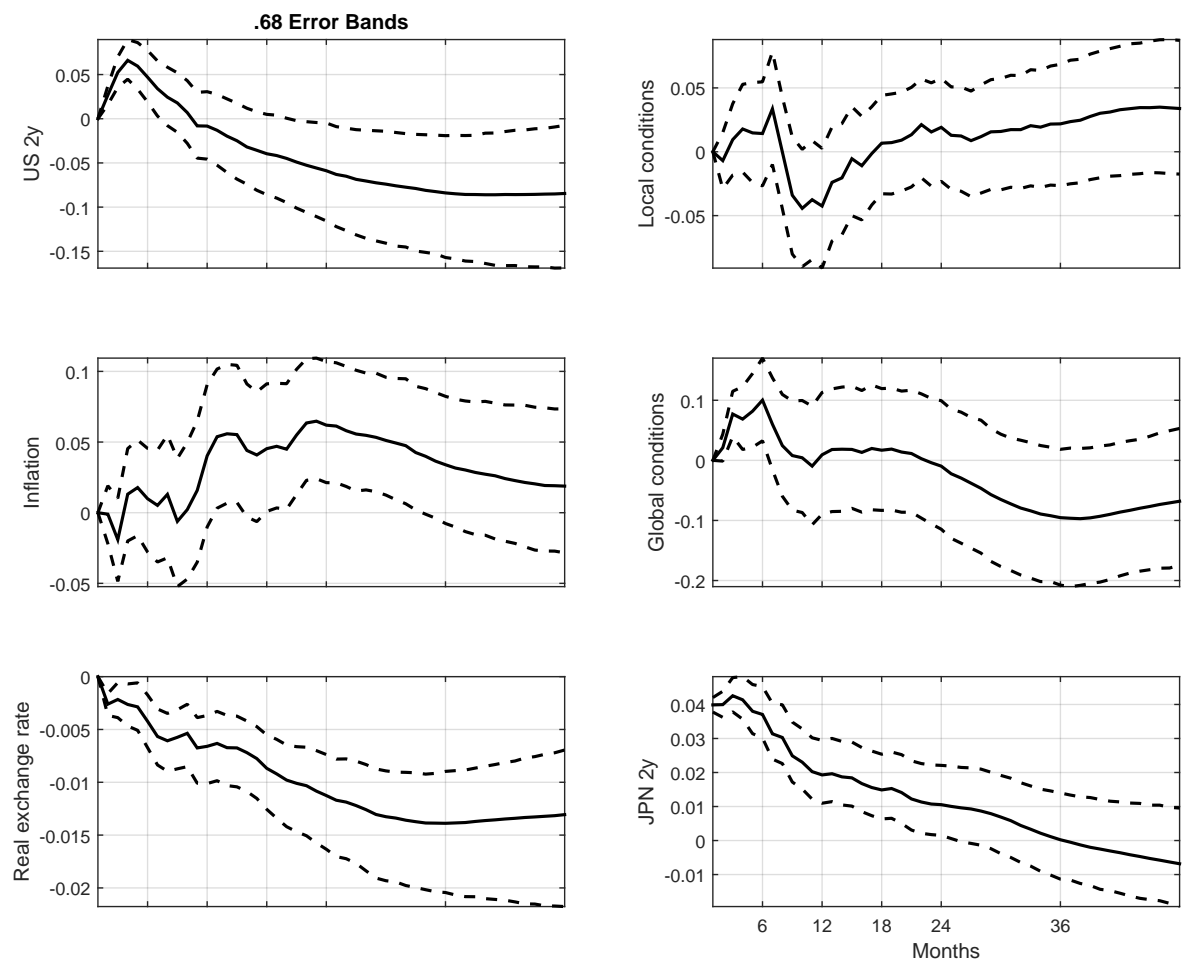

Figure 4. Korea Impulse Response Functions. Impulse responses to a positive shock to the Japan 2-year rate. The solid lines represent estimated impulse responses; dashed lines are $68 \%$ confidence bands. 

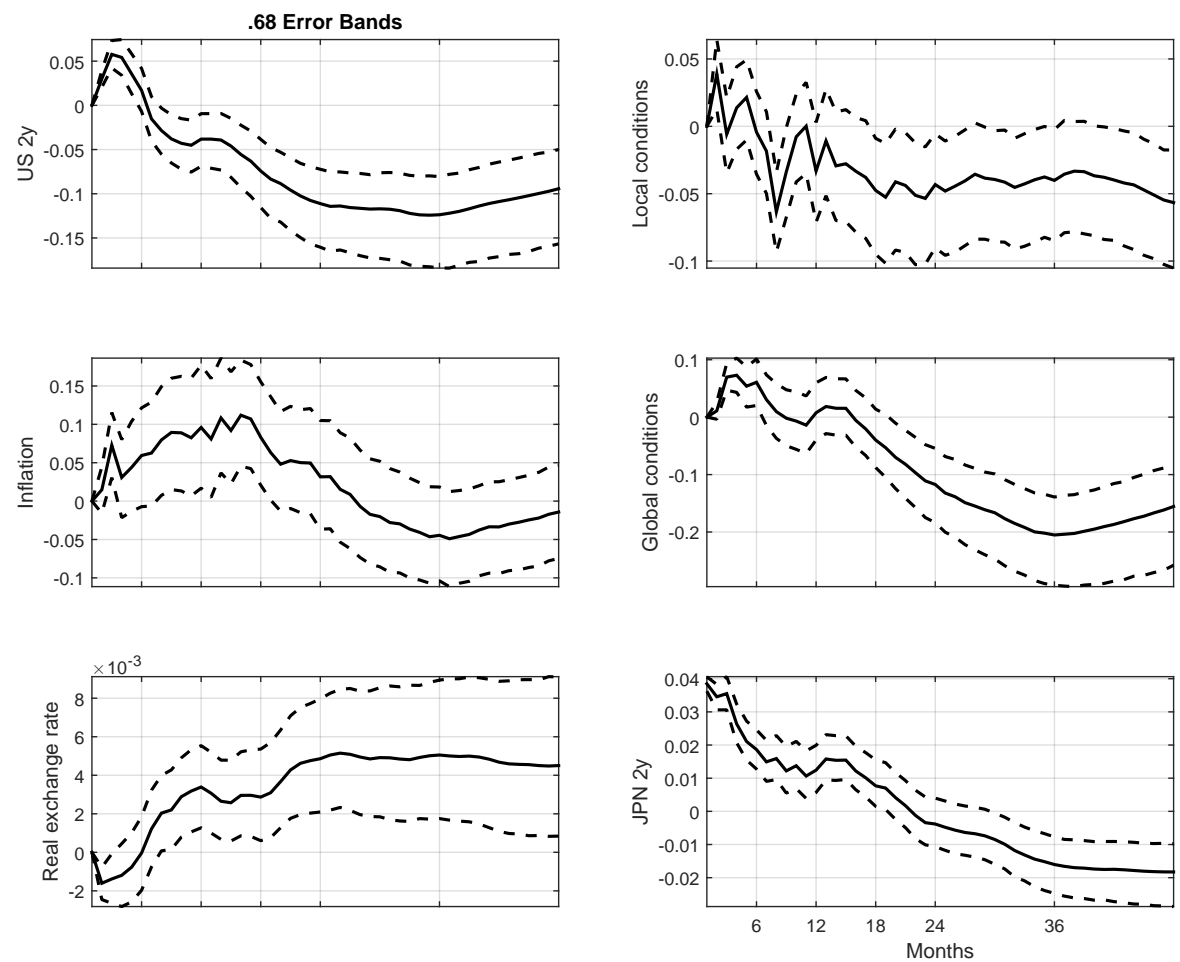

Figure 5. China Impulse Response Functions. Impulse responses to a positive shock to the Japan 2-year rate. The solid lines represent estimated impulse responses; dashed lines are $68 \%$ confidence bands. 

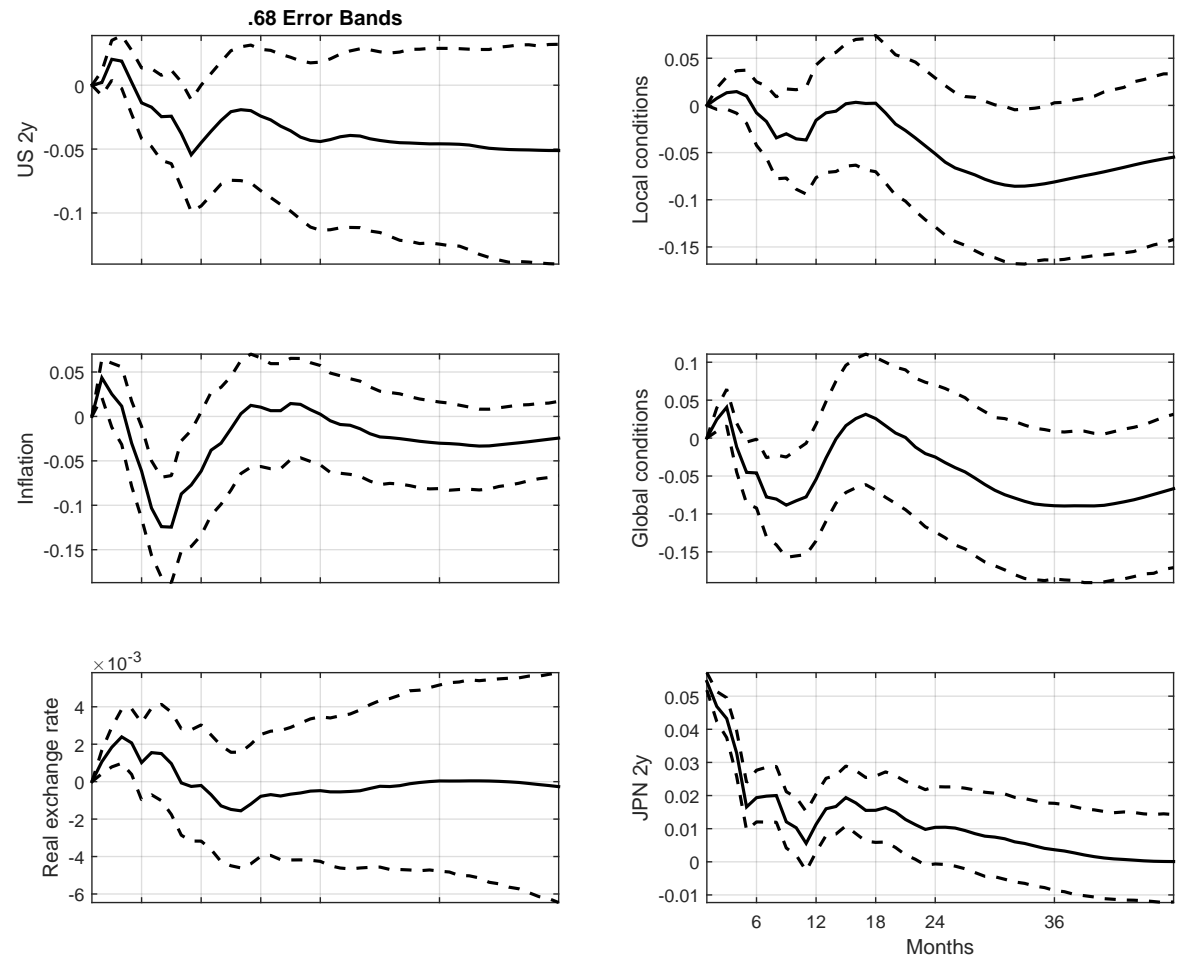

FiguRE 6. United States Impulse Response Functions. Impulse responses to a positive shock to the Japan 2-year rate. The solid lines represent estimated impulse responses; dashed lines are $68 \%$ confidence bands. 

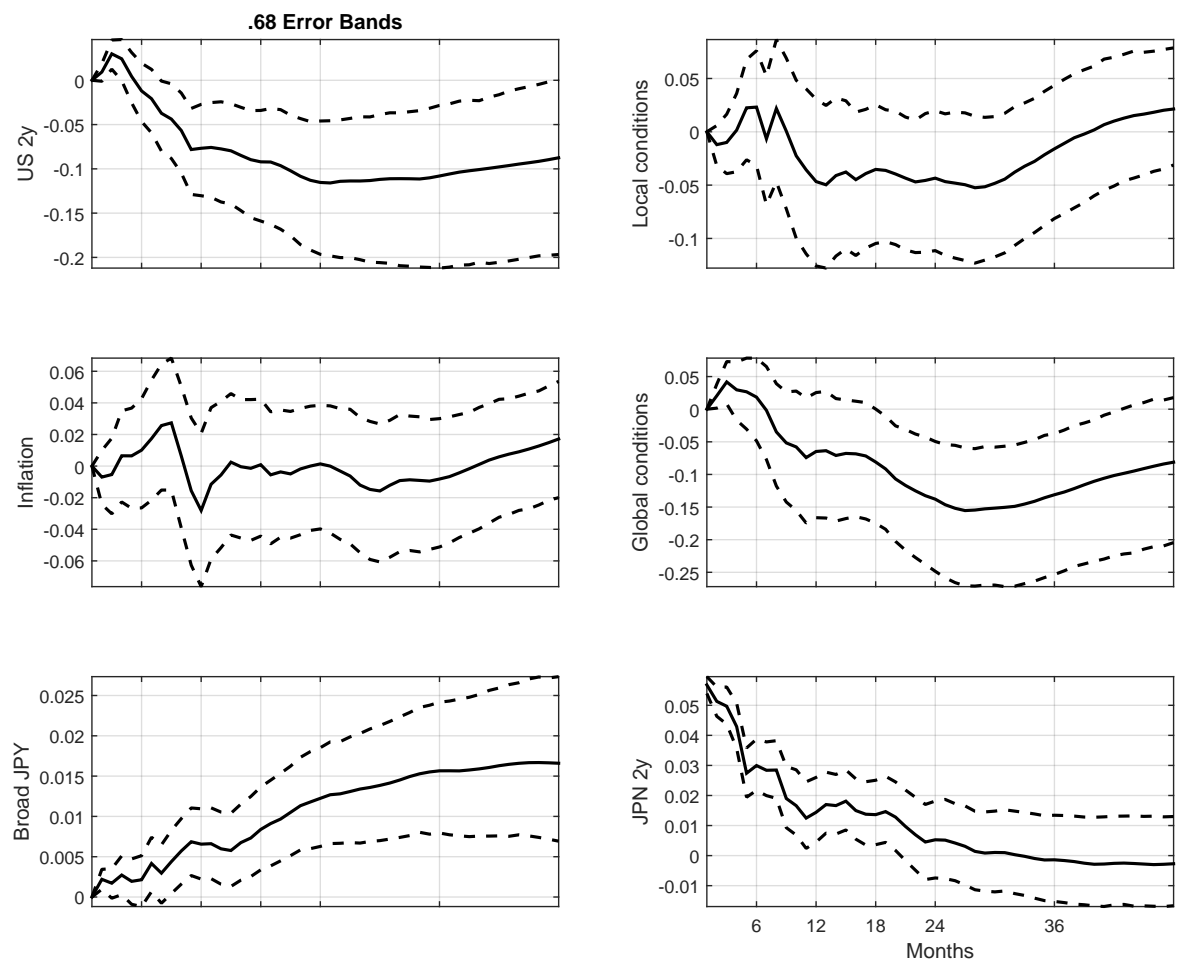

FiguRE 7. Japan Impulse Response Functions using the LCIs excluding interest rates. Impulse responses to a positive shock to the Japan 2-year rate. The solid lines represent estimated impulse responses; dashed lines are $68 \%$ confidence bands. 

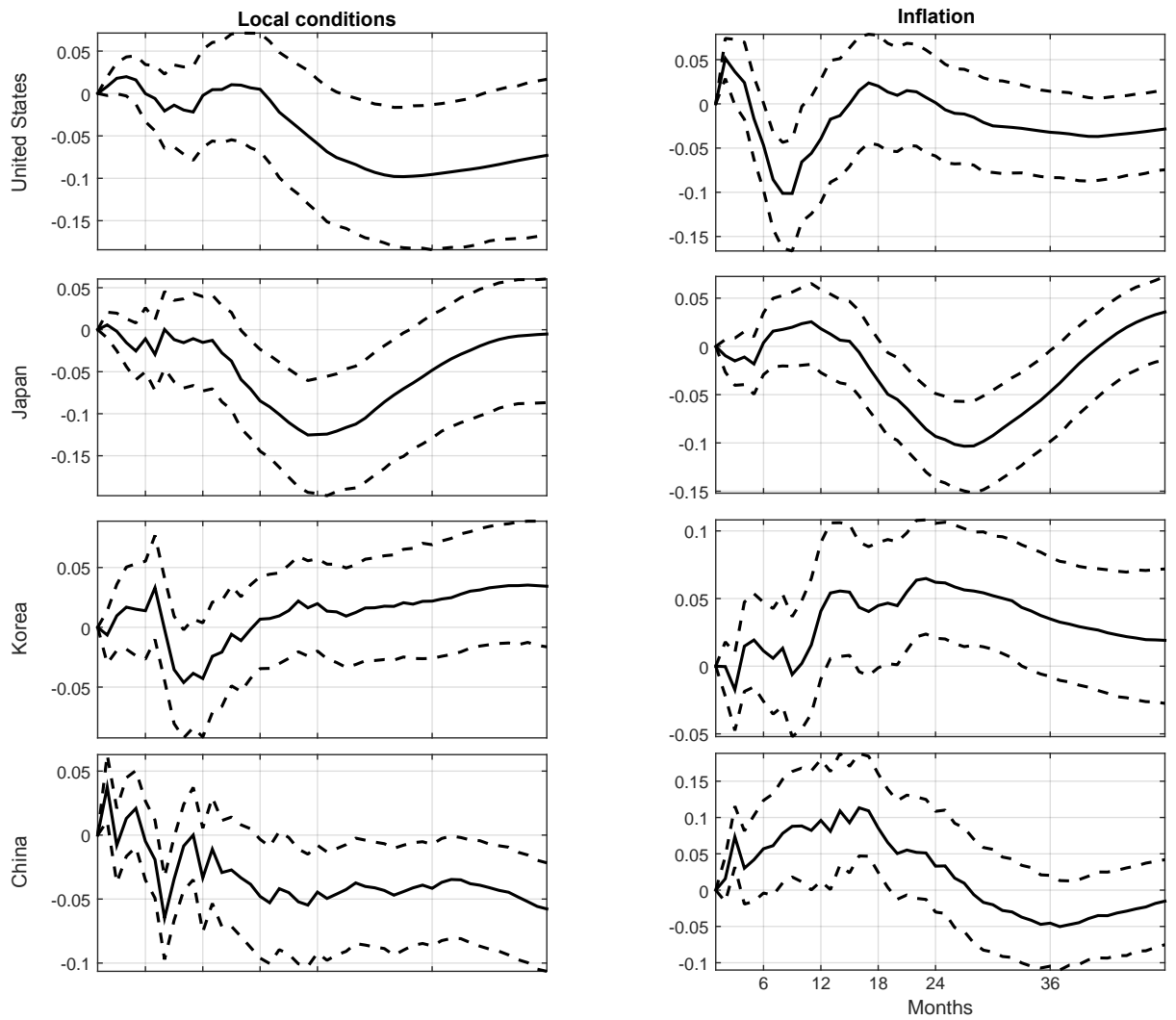

FiguRE 8. Impulse Response Functions with exchange rate ordered last. Impulse responses of Local conditions and inflation to a positive shock to the Japan 2-year rate. The solid lines represent estimated impulse responses; dashed lines are $68 \%$ confidence bands. 